\title{
La práctica del control de constitucionalidad en China
}

The practice of judicial review in China

\section{GUOQIANG ZHAI*}

Resumen: El autor clasifica en tres grupos los modelos de control constitucional en el mundo: el modelo de Tribunal Constitucional, el de revisión judicial y el control parlamentario, ubicando a China en este último. Posteriormente, resalta las dos finalidades principales del control de constitucionalidad: la protección de los derechos humanos y el control de constitucionalidad del sistema legal. Finalmente, el autor plantea el debate sobre el órgano que debería estará cargo del control de constitucionalidad, vale decir, si esa importante labor debe continuar en la Asamblea Popular Nacional, transformarse de un órgano legislativo a uno no legislativo o si debe quedar a cargo de la Corte Superior de China.

Palabras clave: control de constitucionalidad - derechos constitucionales democracia

Summary: The author classifies constitutional control models in the world in three groups: Constitutional Court model, judicial revision and parliamentary control. China's model is the last one. Then, underlines, two main goals of constitutional control: human rights protection and constitutional control of the legal system. Finally, suggests a debate about which body should be in charge of the constitutional control, whether that important work shall continue under the National People's Congress, become a non legislative body or if it shall stay in charge of China's Superior Court.

Key words: constitutional control - constitutional rights - democracy

CONTENIDO: I. INTRODUCCIÓN.- II. CONTROL DE CONSTITUCIONALIDAD: DESDE UNA PERSPECTIVA COMPARADA.- II.1. LA FUNCIÓN PRINCIPAL DEL CONTROL DE CONSTITUCIONALIDAD.- II.2. EL CONTROL DE CONSTITUCIONALIDAD EN CHINA: ¿LA ASAMBLEA POPULAR NACIONAL SE CONTROLA A SÍ MISMA?.- III. EL CONTROL CONSTITUCIONAL Y EL PRINCIPIO DEL IMPERIO DE LA LEY.- IV. CONTROL DE CONSTITUCIONALIDAD Y DEMOCRACIA.- V. EL CONTROL DE CONSTITUCIONALIDAD EN EL FUTURO: ¿CONTROL DE CONSTITUCIONALIDAD DIRIGIDO POR LA CORTE SUPERIOR?.V.1. EL CONTROL DE CONSTITUCIONALIDAD A FIN DE PROTEGER DERECHOS CONSTITUCIONALES.- V.2. ESTRATEGIA Y MÉTODO LEGAL DE LA DECISIÓN CONSTITUCIONAL.- VI. CONCLUSIÓN.

Profesor asociado al Instituto de Derecho de la Academia China de Ciencias Sociales, Secretario general adjunto de la Asociación China de Derecho Constitucional. 


\section{INTRODUCCIÓN}

No existe Tribunal Constitucional ni otro órgano especial encargado de evaluar la constitucionalidad de la acción estatal en China. Pese a que la Constitución y la Ley Legislativa establecen que China dispone del control formal de la Constitución, esta no ha sido habilitada. Según la Constitución de este país, la Asamblea Popular Nacional (NPC) y el Comité Permanente de la Asamblea Popular Nacional (NPCSC) no son solo los más altos órganos legislativos de China, sino también los órganos autorizados para resolver las controversias. Además, son los responsables de asegurar el cumplimiento de la Constitución, así como de interpretarla, al igual que a las demás leyes. La participación de la Asamblea Popular Nacional puede tener gran influencia en la solución de controversias de dos modos: a través del control de constitucionalidad, y por medio de la interpretación constitucional y legal a cargo de la NPCSC, la cual puede influir en la decisión de la Corte y, por lo tanto, producir un impacto indirecto en la solución de la controversia ${ }^{1}$.

Algunos estudiosos argumentan que no existe ningún sistema de control constitucional en China. Por el contrario, el profesor Zhuguobin sostiene que, tomando en consideración a la Constitución china y a la función de resolución de conflictos realizada por las diferentes ramas gubernamentales, podemos concluir que el control constitucional sí está presente en este país, a tal punto que la Constitución establece un sistema de revisión constitucional en el propio Poder Legislativo en lugar de en las Cortes².

\section{CONTROL DE CONSTITUCIONALIDAD: DESDE UNA PERSPECTIVA COMPARADA}

Existen al menos tres diferentes modelos de control constitucional en el mundo. El modelo del Tribunal Constitucional, adoptado por muchos países europeos, consiste en un órgano especial encargado de velar por la constitucionalidad, y en este sentido, mantiene cierta superioridad legal en relación con otras ramas de poder. Esta revisión alcanza a todos los actos legislativos, los cuales son los más altos instrumentos legales de un sistema jurídico y político específico. Una verdadera institución con el poder de brindar un adecuado control constitucional debe ser tal que en un determinado sistema de separación de poderes imponga cierto límite al Poder Legislativo (el Parlamento), de modo que pueda anular las leyes aprobadas por este. Francia es un ejemplo especial de este modelo, ya que el Consejo Constitucional solo puede revisar la constitucionalidad

1 WANG, Zhengmin. Constitutional Conflict and the Role of the National People's Congress. En: http:// www.fljs.org/sites/www.fljs.org/files/publications/Zhenmin\%25231\%2523.pdf

$2 \mathrm{ZHU}$, Guobin. «Constitutional Review in China: An Unaccomplished Project or a Mirage?». Suffolk University Law Review, XLIII (2010), p. 625. 
de las leyes antes de que entren en vigor. El sistema francés realiza un control abstracto, por el cual decide sobre la constitucionalidad de una ley sin haber antes conocido un caso que haya surgido bajo el supuesto de dicha ley. Se emiten opiniones consultivas en lugar de verdaderos juicios.

Además del modelo del Tribunal Constitucional, la Revisión Judicial constituye otro modelo por el cual los tribunales de causas comunes tienen el poder de revisar la constitucionalidad de las acciones del Estado y de las decisiones legislativas. El típico ejemplo de este modelo lo encontramos en Estados Unidos, y en específico en el caso Marbury (1803). Charles Evans Hughes afirmó: «Estamos bajo una Constitución, pero la Constitución es lo que los jueces dicen que es». La revisión judicial constituye una revisión específica y a posteriori, por la cual la Corte Suprema procura la uniformidad de la jurisprudencia. Hoy en día, este modelo ha sido adoptado por muchos otros países fuera de los Estados Unidos, como es el caso del Japón.

El Control Parlamentario es un modelo inusual y distinto de los ya mencionados. En algunos países, son los comités dentro del Parlamento - e incluso el Parlamento mismo- los que llevan a cabo el control de constitucionalidad en el sistema de gobierno. Los ejemplos de este modelo incluyen a Finlandia, Australia, la República Popular China y otros. De conformidad con la Constitución china, el Comité Permanente de la Asamblea Popular Nacional puede definir la Constitución, aunque hasta la actualidad no ha dicho qué es. El Comité Permanente puede derogar cualquier ley o decisión judicial que considere en contra de la Constitución, los estatutos, o normas y los reglamentos administrativos.

\section{II.1. La función principal del control de constitucionalidad}

Hay distintos modelos de control constitucional alrededor del mundo, pero pueden identificarse dos tareas centrales de esta institución, independientemente del modelo que se adopte. La primera es la protección de los derechos humanos consagrados en la Constitución, pues los derechos constitucionales perderían sentido si no existiera mecanismo alguno para su efectiva realización. Los derechos básicos son la prioridad en el derecho positivo, e incluso en la propia Constitución ${ }^{3}$. Tal control, en relación con las normas sobre derechos constitucionales, puede proteger a aquellas de la intervención de los órganos gubernamentales (incluyendo el órgano legislativo).

3 Esto realza la concepción de «la inconstitucionalidad de una norma constitucional». Ver DIETZE, Gottfried. «Unconstitutional Constitutional Norms? Constitutional Development in Postwar Germany». Virginia Law Review, 42 (enero, 1956), pp. 1-22. 
La otra tarea es el control de constitucionalidad del sistema legal. Considerado el imperio de la ley como un principio constitucional básico, la unificación del sistema legal es otra importante función del control de constitucionalidad. El derecho, según Kelsen, es un sistema de normas, y las normas son declaraciones de «deberes» que prescriben ciertos modelos de conducta. Todas las normas dadas por un sistema legal derivan su validez de la Constitución, de modo que un Tribunal Constitucional debe funcionar como un «legislador negativo» encargado de derogar las leyes que son incompatibles con la Constitución.

En China, la Constitución tiene la más alta autoridad legal, así que ninguna ley nacional, reglamento administrativo, reglamento local, reglamento autónomo, reglamento especial ni regla local o administrativa puede contravenirla; la ley nacional (elaborada por la Asamblea Popular Nacional y el Comité Permanente de la Asamblea Popular Nacional) tiene mayor autoridad legal que un reglamento administrativo, decreto local y regla administrativa o local; los reglamentos administrativos (dados por el Consejo de Estado) tienen mayor jerarquía legal que un reglamento local y reglas locales o administrativas; mientras que los reglamentos locales (a cargo de la Asamblea Popular y sus comités permanentes en las diferentes provincias) superan la autoridad legal de las reglas locales emitidas por los gobiernos en los mismos o inferiores niveles, y estas últimas (promulgadas por el Gobierno Popular de las provincias, regiones autónomas y municipios) prevalecen sobre las reglas locales dictadas por el Gobierno Popular de la «gran ciudad» localizada en su jurisdicción ${ }^{4}$.

\section{II.2. El control de constitucionalidad en China: ¿la Asamblea Popular Nacional se controla a sí misma?}

El Sistema de la Asamblea Popular es el sistema constitucional básico de China. La Constitución de la República Popular China prescribe que el poder del Estado pertenece al pueblo. La Asamblea Popular Nacional y las Asambleas Populares Locales, en todos los niveles, son los órganos a través de los cuales las personas ejercen el poder del Estado. Dichas asambleas se constituyen por medio de elecciones democráticas, son responsables ante el pueblo y están sujetas a su supervisión. Los órganos administrativos, judiciales y fiscales del Estado son creados por la Asamblea Popular, frente a quien son responsables y fiscalizados. La Asamblea Popular Nacional se reúne solo una vez al año, y cada sesión dura entre diez días y dos semanas. Tiene alrededor de 2900 miembros y 9 subcomités. Sin duda, es

4 ZHU, Guobin. Ob. cit., p. 625. 
técnicamente imposible para la Asamblea Popular Nacional ejercitar de manera frecuente su función como «Tribunal Constitucional».

En este sentido, la Constitución China autoriza al Comité Permanente de la Asamblea Popular Nacional llevar a cabo la revisión constitucional. Este Comité cuenta con 175 miembros y se reúne cada dos meses, lo que le permite desarrollar su rol de manera mucho más efectiva. En virtud de la Constitución, el Comité Permanente de la Asamblea Popular Nacional tiene el poder de interpretar la Constitución y supervisar su ejecución; interpretar estatutos; anular las reglas y reglamentos administrativos, decisiones, y órdenes del Consejo de Estado que contravengan la Constitución o sus estatutos; así como anular los reglamentos locales o decisiones de los órganos del Estado o de las provincias, regiones autónomas y municipalidades que contradigan la Constitución, sus estatutos, o los reglamentos y reglas administrativas ${ }^{5}$.

El artículo 67 de la Constitución china autoriza al Comité Permanente de la Asamblea Popular Nacional ejercitar las funciones y poderes de «interpretar la Constitución y supervisar su ejecución», «anular las reglas y reglamentos administrativos, decisiones y órdenes del Consejo de Estado que contravengan la Constitución o la ley», y «anular los reglamentos locales o decisiones de los órganos de poder estatal de las provincias, regiones autónomas y municipalidades que contravengan la Constitución, la ley o las reglas y reglamentos administrativos». En 2004, el Comité Permanente de la Asamblea Popular Nacional anunció la formación de una nueva Legislation Review and Filing Office (LRFO) para apoyar a su Legislative Affairs Commission en el control de las regulaciones que puedan entrar en conflicto con la Constitución y las leyes nacionales. Se trata de una implementación de la Legislation Law que autoriza al Comité Permanente de la Asamblea Popular Nacional a actuar frente a las propuestas de los ciudadanos solo «cuando sea necesario». El Comité Permanente de la Asamblea Popular Nacional no está obligado a informar a los ciudadanos si es que actuará o no respecto de una determinada propuesta.

El control de constitucionalidad llevado a cabo por la Asamblea Popular Nacional ha sido una de las principales corrientes de opinión en China. Dicha asamblea constituye un órgano legislativo, de modo que surge la pregunta de cómo evitar que la Asamblea Popular Nacional se controle a sí misma. A la larga, la revisión debe ser hecha por un órgano independiente del legislativo. La pregunta es ahora si parte de la Asamblea Popular Nacional puede transformarse de un órgano

5 WANG, Zhengmin. Constitutional Conflict and the Role of the National People's Congress. En: http:// www.fljs.org/sites/www.fljs.org/files/publications/Zhenmin\%25231\%2523.pdf 
legislativo a uno no legislativo, y si en tal caso puede este órgano convertirse en un tribunal cuasi constitucional.

\section{EL CONTROL CONSTITUCIONALY ELPRINCIPIO DEL IMPERIO DE LA LEY}

En China, el principio del imperio de la ley está llamado a construir un país socialista reglado por la ley, lo que no es más que la formación de un socialismo con características propias de China. En la actualidad, China se encuentra implementando una profunda defensa a este principio, y es que acelerar la construcción de un país socialista regido por el imperio de la ley se ha convertido en un consenso entre la población.

De acuerdo con la investigación del famoso sociólogo Fei Xiaotong, la sociedad tradicional de China es una sociedad "cara a cara», así que las relaciones interpersonales allí difieren de las que se presentan en Occidente. En concordancia con el estudio de Fei, la sociedad occidental es una estructura grupal, mientras que la estructura de la sociedad china constituye un «patrón de diferenciación». Las relaciones entre las personas dentro de una sociedad forman una red muy compleja.

El control social tradicional en China se basa en las relaciones de complementariedad. China y algunos otros países asiáticos han adoptado una relación basada en el control social. Este es el denominado modelo de relation-based governance («gobierno basado en las relaciones»), el cual es distinto del modelo de rule-based governance («gobierno basado en las leyes»). A menudo la población china se autodenomina «sociedad humana», lo cual significa que el control social depende de las relaciones entre las personas. Este modelo tiene ciertas ventajas, como el bajo y flexible costo. En una sociedad tradicional china, en una sociedad de cara a cara, el modelo de relation-based governance ha jugado un importante rol. Sin embargo, y debido al rápido desarrollo económico en China, ha sido muy difícil mantener ese modelo tradicional de control, al punto que el modelo de sociedad cara a cara ha colapsado.

Distinto del modelo de relation-based governance es el modelo de rule-based governance, donde todo el gobierno está estructurado en concordancia con el sistema jurídico. Haciendo una comparación, los modelos de rulebased governance demandan mayores costos, y ello debido a la existencia de órganos independientes legislativo, ejecutivo y judicial. Empero, una vez que la comunidad alcanza cierto tamaño, el uso de tal modelo de gobierno juega un rol muy importante. Precisamente China está camino a convertirse de un gobierno de relation-based a uno de rule-based, de modo que para alcanzar el rule-based governance el crear un sistema jurídico constituye una importante tarea. 
Desde hace una década China ha venido fortaleciendo el sistema jurídico, y desde hace pocos años la Asamblea Popular Nacional de China se concentra en la legislación con el fin de formar un «sistema jurídico socialista». Desde hace tres décadas China ha experimentado una etapa de rápido desarrollo de centralismo legal. En 2003, la legislación china declaró que se había conformado ya el sistema jurídico socialista con características chinas.

Según estadísticas relevantes, como la de agosto de 2009, la Asamblea Popular Nacional y su Comité Permanente promulgaron 229 leyes que se encuentran ahora en vigor, entre las cuales hallamos normas constitucionales, civiles, comerciales, administrativas, económicas, sociales, penales, de procedimientos contenciosos y no contenciosos, y leyes de otros siete sectores más. Por su parte, el Consejo de Estado formuló un total de 682 reglamentos administrativos, mientras que la Asamblea Popular promulgó más de 7000 reglamentos y leyes locales. Sin embargo, el contenido de las leyes es una cosa, y su efectiva realización es otra. En el presente, lograr la efectividad de las leyes sigue teniendo muchos obstáculos, lo cual representa una amenaza para los derechos humanos.

En primer lugar, porque la no efectividad de tales normas reduce las expectativas razonables de las personas. En segundo lugar, este problema puede por sí solo dar lugar a tratamientos diferenciados. Pero el sistema legal aún es imperfecto, y ello se observa en la contradicción entre las normas legales. Una vez añadido el sistema legal, la era del centralismo legislativo estará por terminar. El nuevo período pondrá especial énfasis en la efectividad de la ley y el proceso de implementación. La tarea básica del control de constitucionalidad es fortalecer la supervisión del proceso legislativo. Una efectiva forma es la creación de un sistema de control constitucional acompañado del proceso legislativo.

\section{CONTROLDECONSTITUCIONALIDADY DEMOCRACIA} Las dolorosas experiencias de la pasada guerra y del fascismo dieron lugar a la idea de que el control de constitucionalidad es una característica de la democracia constitucional. Debido a la idea de la supremacía de la Constitución en lugar del principio de soberanía parlamentaria, se dio nacimiento al control de constitucionalidad. Eso quiere decir que el valor interno fundamental de la Constitución es superior a cualquier decisión del Parlamento.

Desde una óptica histórica, la evolución del constitucionalismo en el mundo ha atravesado distintas etapas. Frente a los problemas respecto de la democracia representativa, el dispositivo del control 
de constitucionalidad se ha instaurado de manera universal. En otras palabras, como un beneficioso suplemento de la democracia representativa, el control de constitucionalidad puede suplir el vacío entre el significado y el fin de la democracia ${ }^{6}$.

En China, el Poder Judicial se denomina «el tribunal del pueblo» y todos los jueces son elegidos por la Asamblea Nacional Popular. En el pasado, el maoísmo (el pensamiento de Mao Zedong) fue la ideología central. Si hablamos de este, es necesario remitirnos a la idea de Liang Qichao (un estudioso y político chino anterior a Mao). Cuando se entrevistó con el reportero norteamericano Snow, Mao admitió que el pensamiento de Liang, absolutamente rousseauniano, lo impactó sobremanera, de modo que, a través del pensamiento de Liang Qichao, la ideología del rousseaunismo influyó indirectamente en el maoísmo. Cuando habló sobre la concepción del constitucionalismo, Mao concluyó que «el constitucionalismo era nada más que la democracia» ${ }^{7}$. Esta opinión impactó en la Constitución de la República Popular China de 1954.

El principio de soberanía popular es una de las más importantes partes de la Constitución, de modo que el control de constitucionalidad en China encontrará la mayoría de dificultades en la revisión judicial en otros países. A diferencia de la democracia en Occidente, la creencia en la soberanía absoluta e ilimitada no ha pasado de moda, y la teoría de la soberanía ha sido usada por conservadores chinos para resistirse a la internacionalización del derecho constitucional. El desarrollo de la democracia en China aún es insuficiente, de modo que la soberanía popular existe primordialmente en el texto constitucional y otros documentos, mas no en la realidad.

En concordancia con el texto de la Constitución, la Asamblea Popular Nacional supervisa tanto la SPC (la más alta autoridad judicial china) como el Consejo de Estado (el Poder Ejecutivo), pero en el efectivo proceso constitucional, la Asamblea Popular Nacional no es la autoridad central. Al lado de la $\mathrm{CPPCC}^{8}$, la Asamblea Popular Nacional incluso es considerada como un órgano de consulta. China está camino a la democracia popular y el Poder Ejecutivo sigue siendo el órgano central del sistema de gobierno. Muchos estudiosos han recomendado una reforma en las relaciones entre el sistema de partidos y el sistema de gobierno. La realidad no es afirmativa. Dada la democracia popular

6 Para la teoría del fortalecimiento de la representación, ver ELY, John Hart. Democracy an Distrust: A Theory of Judicial Review. Cambridge: Harvard University Press, 1980.

7 ZEDONG, Mao. On New Democratic Constitutionalism.

8 La CPPCC es una organización de consulta en la institución política. Se mantuvo al mismo tiempo que la entrevista convocada por la NPC. Todos los miembros del CPPCC fueron ubicados en el segundo piso del Gran Salón Popular, mientras que los miembros del NPC se ubicaron en el primer piso. Su función incluía ofrecer consejos a todos los órganos gubernamentales de China (incluso a la Corte Superior). Esta debe ser vista como una constitución no escrita en China. 
en China, la norma constitucional sobre la soberanía popular está en vigor y el fortalecimiento del poder de la Asamblea Popular Nacional resulta una tarea esencial y urgente.

La revisión judicial de las decisiones de la Asamblea Popular Nacional podría dar lugar a una respuesta reacia. Considerando esto, es apropiada en el presente la revisión de otras acciones, excepto las del sistema legislativo.

Con respecto a la relación entre el control de constitucionalidad y la democracia, hay algunas características comunes entre las distintas constituciones en el mundo, pero las diferencias son obvias. Lo más resaltante de la Constitución democrática es que coloca a la soberanía popular en una posición muy importante. Este es un factor clave de la relación entre el control de constitucionalidad y la democracia. Cuando llegue a China, la democracia popular será la ideología central, aun cuando la democracia en sí misma no se haya institucionalizado por completo.

\section{EL CONTROL DE CONSTITUCIONALIDAD EN EL FUTURO: ¿CONTROLDE CONSTITUCIONALIDAD DIRIGIDO POR LA CORTE SUPERIOR?}

La Constitución inviste a la Asamblea Popular Nacional de autoridad suprema entre todos los poderes del sistema de gobierno, pese a que ello no es efectivo en la realidad. Los poderes ejecutivo y judicial son elegidos por la Asamblea Popular Nacional. Esta, además, supervisa tanto a la SPC, la más alta autoridad judicial en China, como al Consejo de Estado; es decir, a la autoridad ejecutiva.

Esto confirma que actualmente todo el poder del Estado está centralizado en un sistema en el que no existe separación de poderes. Se considera que esta forma de poder altamente centralizada tiene sus raíces en las prácticas gubernamentales que se llevaron a cabo bajo el Partido Comunista de China (CPC) en las décadas de 1930 y 1940.

Este sistema centralizado es radicalmente distinto de la convencional concepción que se tiene en Occidente sobre la separación de poderes. Pese a que parece ser un sistema parlamentario, considerando que la Asamblea Popular Nacional es el más alto poder en China, el sistema de la Asamblea Popular es completamente diferente; así, vemos que la creación de los órganos judiciales está sujeta a la decisión de la Asamblea, y más importante aún, la NPC no se organiza a través del sufragio universal'.

LA PRÁCTICA

DEL CONTROL DE CONSTITUCIONALIDAD EN CHINA

THE PRACTICE OF JUDICIAL REVIEW IN CHINA 
Antes del año 2001, la Corte Superior de China nunca había aplicado las disposiciones constitucionales. En un caso sobre el derecho a la educación (caso Qi Yuling, 2001), la Corte Suprema revisó sus decisiones de los años 1955 y $1988^{10}$. El juicio fue bastante corto, pero el juez publicó un largo artículo sobre el caso y afirmó que la Corte tenía la responsabilidad de interpretar e incidir en el desarrollo de la Constitución. Pero en 2008, la Corte Superior invalidó la interpretación realizada en el caso Qi Yuling.

Algún estudioso del tema denominó a este hecho «la muerte del litigio constitucional en China ${ }^{11}$, de modo que la mayoría de estudiosos chinos piensa que la Revisión Judicial es un excelente modelo de control de constitucionalidad. No obstante, no existen suficientes consideraciones en favor de su implementación en China, así que no resulta factible copiar este modelo. La revisión judicial de la constitucionalidad depende en gran medida de la existencia de la separación de poderes y los controles y contrapesos. Es casi imposible que esta prospere en el sistema chino de la Asamblea Popular, caracterizado por su insistencia en la supremacía de la Asamblea Popular y su resistencia a la separación de poderes. En definitiva, cada mejora legal debe basarse en el contexto constitucional actual en China.

\section{V.1. El control de constitucionalidad a fin de proteger derechos constitucionales}

En los últimos años, el Partido Comunista Chino propuso el desarrollo del concepto «poner al pueblo primero». En consecuencia, la protección de los derechos humanos ha sido vista como un principio básico del sistema legal en China. En adición al establecimiento de principios sobre derechos humanos en la Constitución, el Gobierno Central Chino formuló el «Plan de Acción de Derechos Humanos». Con relación a las personas con orientaciones políticas, la legislación china enfatiza la protección de los derechos a la vida y al desarrollo. Así que el «derecho social» se convirtió en una parte importante del sistema legal socialista. Para lograr un desarrollo económico y social sostenibles, el derecho ambiental también es un importante contenido del sistema legal chino.

Tomando en cuenta el valor del respeto a los derechos humanos, resulta factible adoptar el control de constitucionalidad para protegerlos. En este sentido, los sistemas jurídicos externos pueden proporcionar algunas referencias. Debido a la universalidad de los derechos constitucionales básicos, la doctrina de los derechos constitucionales puede ser usada como

10 En estas dos decisiones, el juez puntualizó que la Constitución no podía ser aplicada en un caso ordinario, como uno civil o penal.

11 KellogG, E. «¿La muerte del litigio constitucional en China?». China Brief, 9. 
referencia en los diferentes procesos de control de constitucionalidad. Algunas doctrinas constitucionales en países europeos son similares a la jurisprudencia constitucional de las Cortes Superiores de Estados Unidos. Por ejemplo, la ripeness and standing doctrine («doctrina de la madurez y la permanencia/continuidad»), y la doctrina de la igualdad en la protección. Por otro, la doctrina de los derechos constitucionales de la Corte Constitucional de Alemania puede además fundarse en otro sistema de modelo de control de constitucionalidad, de modo que es posible estudiar la doctrina constitucional de otros países e importarla al sistema de control de constitucionalidad. Muchos casos constitucionales en otros países estuvieron vinculados con la protección de derechos básicos; estas doctrinas pueden servir como referencia a los abogados chinos para interpretar las normas sobre derechos básicos contenidas en el texto constitucional. En este entendido, la doctrina de los derechos fundamentales en otros países puede ser muy útil para China, y la experiencia puede además despertar entre los especialistas chinos el ánimo estudiar el control de constitucionalidad en conexión con los derechos humanos internacionales.

Una característica especial de este procedimiento es que cualquier ciudadano puede presentar un recurso de inconstitucionalidad a la Comisión Permanente de la Asamblea Popular Nacional, aun cuando no se vea directamente afectado por el fondo de la queja, sin que sea necesaria la existencia de una controversia real. En contraste con esto, bajo el sistema del Common Law, una persona debe tener una relación sustancial con la disputa, la cual debe, además, existir antes de que las partes presenten un caso de control de constitucionalidad ante la Corte. Desde el año 2000, muchos de estos tipos de propuesta de control de constitucionalidad han sido incorporados en la Comisión Permanente de la Asamblea Popular Nacional.

\section{V.2. Estrategia y méto do legal de la decisión constitucional}

Los métodos legales tienen algunas características comunes en los diferentes modelos de control de constitucionalidad. Por ejemplo, el método de interpretación de las normas en conformidad con la Constitución ha sido adoptado en diferentes modelos de control de constitucionalidad $^{12}$. En algunos casos, con el fin de proteger derechos individuales afectados por la aplicación del derecho, la Corte usó este método para armonizar la contradicción entre la protección de los derechos individuales y la democracia. Pero esta técnica no puede operar sin restricciones, ya que la interpretación excesiva del texto

12 Ver Donald P. Kommers y Russell A. MILLER. The Constitutional Jurisprudence of the Federal Republic of Germany. Durham: Duke University Press, 1989, p. 541; William J. NARDINI. «Passive Activism and the Limits of Judicial Self-Restraint: Lessons for America from the Italian Constitutional Court». Seton Hall Law Review, 30 (1999), pp. 1-63. 
legal es una usurpación de la función legislativa. Así que la Corte debe ejercitar esta técnica legal con cautela y deferencia (autolímite judicial).

El artículo 67 de la Constitución de la República Popular China autoriza al Comité Permanente de la Asamblea Popular Nacional «interpretar la Constitución y supervisar su ejecución» y «anular las reglas y reglamentos administrativos, decisiones y órdenes del Consejo de Estado que contravengan la Constitución o la ley». En el año 2004, el Comité Permanente de la Asamblea Popular Nacional anunció la formación de una nueva Legislation Review and Filing Office (LRFO) encargada de apoyar a su Legislative Affairs Commission en la revisión de los reglamentos que puedan entrar en conflicto con la Constitución. Esta es una implementación de la Legislation Law, pero el derecho solo dispone que el Comité Permanente de la Asamblea Popular Nacional puede responder a los propósitos de los ciudadanos «cuando sea necesario». El Comité Permanente de la Asamblea Popular Nacional no requiere informar a los ciudadanos si va a actuar o no en un propósito concreto. Entonces, cómo despertar el control de constitucionalidad en el texto constitucional es aún una tarea urgente para los abogados chinos. Para lograr el funcionamiento del sistema del control de constitucionalidad, muchos han llevado sus quejas al Comité Permanente de la Asamblea Popular Nacional, e insisten en que aquel debe elaborar una decisión inconstitucional.

Hablando de manera general, una de las funciones más importantes del control de constitucionalidad es hacer respetar el valor constitucional en todo el sistema legal. Pero un mero juicio de inconstitucionalidad no puede promover la incorporación del sistema legal al orden constitucional. Dado el carácter especial de los casos constitucionales, los jueces constitucionales a menudo adoptan diferentes modelos de decisión de inconstitucionalidad para mantener el balance con el poder político en el proceso del control de constitucionalidad. En tanto que no existe sistema de control de constitucionalidad maduro y perfecto en China, pueden usarse distintos modelos de decisiones constitucionales en diferentes países como referencia para despertar el control de constitucionalidad en el texto constitucional. En diversos sistemas de control de constitucionalidad, los modelos de decisiones de inconstitucionalidad pueden clasificarse en tres tipos: la decisión inconstitucional y nula, la mera declaración de inconstitucionalidad y la decisión exhortativa. Los diferentes modelos que combinan técnicas legales y juicios políticos pueden ser la referencia para catalizar el efectivo control de constitucionalidad en China.

De acuerdo con la disposición constitucional y la Legislative Law, China tiene además un control de constitucionalidad formal, pero 
que aún no ha sido habilitado. La Constitución no se ha convertido en el estándar para juzgar el comportamiento de los órganos del Estado o de los ciudadanos. El profesor Mojihong argumentó que, para mejorar la condición jurídica de la Constitución, es imperativo que la Asamblea Popular Nacional y su Comité Permanente instalen agencias que se encarguen de las tareas concretas respecto de la supervisión de la implementación constitucional. En la actualidad, lo más importante para la construcción institucional es implementar las disposiciones relevantes en la Legislative Law respecto del control de constitucionalidad.

El sistema de la Asamblea Popular Nacional también puede brindar un espacio de ejercicio por encima de las ya mencionadas técnicas legales. Sin embargo, algunos conservadores aún temen las criticism base on unconstitutional reason («críticas basadas en razones de inconstitucionalidad»). Para el sistema constitucional en el que el control de constitucionalidad efectivo está ausente, el primer paso consiste en pronunciar una decisión constitucional actual. $\mathrm{Al}$ inicio de la práctica de la decisión constitucional, el Comité Permanente de la Asamblea Popular Nacional puede adoptar una decisión cuasi exhortativa como un paso preparatorio, teniendo en consideración la opinión tradicional.

\section{CONCLUSIÓN}

La reforma social en China, que se inició en el campo económico, se centra también en el desarrollo económico en los primeros años de la reforma. Por consiguiente, China cuenta con algunas enmiendas previas de contenido económico. En los últimos treinta años, la tendencia de la reforma económica en China consiste en desarrollar y mejorar la «economía socialista de mercado». Con el cambio de la economía planificada a una economía de mercado, la idea del nacionalismo ha ido decayendo. Esto también conduce a transformaciones respecto de los conceptos de la teoría del derecho público y de la reforma institucional, tales como el establecimiento de procesos contenciosos administrativos, el derecho legislativo o la ley sobre la supervisión.

El sistema de la Asamblea Popular es el sistema constitucional básico de China. El control de constitucionalidad hecho por la Asamblea Popular Nacional ha sido una de las más importantes corrientes de opinión en China. El profesor Wangzhenmin argumentó que el Consejo Constitucional o una Comisión en la Asamblea Popular Nacional sería el órgano más adecuado a través del cual China puede establecer su constitucionalismo e imperio de la ley. Algunos comentaristas han sugerido que la SPC debe estar autorizada a llevar a cabo las tareas del control de constitucionalidad y la interpretación constitucional. Esta opinión no es realista, pues el sistema de Asamblea Popular en China

LA PRÁCTICA

DEL CONTROL DE CONSTITUCIONALIDAD EN CHINA

THE PRACTICE OF JUDICIAL REVIEW IN CHINA 
es el sistema político fundamental. Por otra parte, los tribunales de causas comunes no tienen la credibilidad necesaria para ejercitar este importante poder.

A pesar de ello, si se establece un Consejo o Comité Constitucional, la responsabilidad de los tribunales ordinarios en la protección de los derechos fundamentales no debe ser cumplida en su totalidad. Lo que los tribunales ordinarios no deben hacer es llevar a cabo el control de constitucionalidad abstracto sobre actos, reglamentos e interpretación constitucional. Debe existir una división de labores entre el deseable Consejo o Comité Constitucional y los tribunales ordinarios, mediante el cual el primero sea responsable del control de constitucionalidad abstracto y de la interpretación constitucional, mientras que los otros asuman la responsabilidad de proteger los derechos constitucionales concretos de los ciudadanos.

El problema principal para el examen de constitucionalidad en China es la forma como hacer efectiva la decisión constitucional. Por un lado, el control de constitucionalidad puede mejorar la legitimidad de las acciones gubernamentales, y más aun cuando este es un factor básico en concordancia con el principio del imperio de la ley. Desde que el Partido quiere gobernar al país de conformidad con la ley, el control de constitucionalidad es una institución necesaria. Por otro lado, técnicas jurídicas para la institución deben ser construidas en el futuro. Estas técnicas pueden ser comunes para los abogados constitucionalistas en otros países, pero todavía es un buen momento de estudiar estas técnicas para los abogados chinos, de modo que la doctrina constitucional pueda extraerse del texto constitucional chino. 